\title{
Padre Vieira e os filhos de Tupá (Um conto esquecido de Firmino Rodrigues da Silva)'
}

\author{
Father Vieira and the sons of Tupá \\ (A forgotten tale of Firmino Rodrigues da Silva)
}

\author{
WILTON MARQUES
}

Universidade Federal de São Carlos

\section{Um prólogo necessário}

No longo processo de consolidação da literatura brasileira ao longo do século XIX, a temática indianista ocupou provavelmente o lugar mais importante no ideário romântico local, pois, com seu progressivo desenvolvimento artístico, o indígena foi "simultaneamente guindado à posição de objeto estético, herói literário e antepassado mítico histórico" (GALVÃO, 1979, p. 383). Por isso, no caso da cultura brasileira, não chega a ser surpreendente que, ao também invadir o espaço de outras formas de arte, além, é claro, da literária, $\mathrm{o}$ indianismo tenha praticamente se confundido com o romantismo. Nesse sentido, e à força de muita repetição, a sobrevalorização simbólica do "brasileiro autêntico" afirmou-se na literatura, sobretudo em função da evidente ressonância in loco dos projetos estético-literários de Gonçalves Dias e de José de Alencar.

Entretanto, anterior aos aparecimentos literários do poeta maranhense e do romancista cearense, um outro autor, ilustre desconhecido nos dias de hoje, também desempenhou um papel singular no início do processo de afirmação literária da temática indianista. Trata-se de Firmino Rodrigues da Silva (1815-1879). Jornalista e panfletário de destaque nos quadros do Partido Conservador e que, mais tarde, seria juiz, deputado e, finalmente, senador do Império, Firmino, sem nunca ter publicado uma obra de viés literário, sempre aparece ao longo da história literária oitocentista, citado aqui e ali, como o autor de um poema que é considerado um dos primeiros de feição propriamente indianista, a "Nênia à morte do meu bom amigo o Dr. Francisco Bernardino Ribeiro". Datado de 15 de setembro de 1837, mas somente

\footnotetext{
1 Tanto a transcrição do conto de Firmino Rodrigues da Silva quanto os eventuais fragmentos aqui reproduzidos tiveram sua ortografia atualizada. No entanto, no que se refere aos demais aspectos expressivos, procurou-se preservá-los tais quais estão nas diversas publicações, sobretudo os que se referem à pontuação, ainda que, em alguns momentos pontuais, signifique menosprezar as regras atuais.
}

publicado num periódico político-partidário - o jornal $O$ Brasil -, em 16 de março de 1841, e, portanto, cinco anos antes de Gonçalves Dias e seus Primeiros cantos (1846), este poema de Firmino foi recorrentemente lido por autores e críticos como um referencial importante para a definição do indianismo romântico ${ }^{2}$.

Mas antes mesmo da publicação da famosa nênia, Firmino Rodrigues, ao dar seus primeiros passos no jornalismo, também publicou, no início de 1838, três pequenos contos na imprensa carioca. Nessa perspectiva, no dia 7 de janeiro, apareceu "Um sonho"3 no Gabinete de Leitura (1837-1838). No dia 13 de janeiro, "Os três desejos"4 e, finalmente, no dia 5 de fevereiro, "Mariana Pinta" , ambos no folhetim literário Apêndice do jornal O Cronista (1836-1839). A publicação dos contos nesses dois periódicos não foi obra do mero acaso, já que Firmino, então advogado recém-formado, possuía uma forte relação de amizade, que vinha dos tempos da academia em São Paulo, com Justiniano José da Rocha e Josino do Nascimento Silva. Em 1836, os dois amigos fundaram $O$ Cronista ${ }^{6}$, e, em 1837, Josino criou o Gabinete de Leitura?

\footnotetext{
2 Para maiores detalhes sobre a importância literária do poema de Firmino Rodrigues da Silva bem como sobre sua repercussão na literatura oitocentista brasileira, ver Marques (2015).

3 SILVA, Firmino Rodrigues. Um sonho. Gabinete de Leitura, Rio de Janeiro, 7 jan. 1838, n, 22, p. 175-176.

4 SILVA, Firmino Rodrigues. Os três desejos. O Cronista, Rio de Janeiro, 13 jan. 1838 , n. 130, p. 1-3

5 SILVA, Firmino Rodrigues. Mariana Pinta. O Cronista, Rio de Janeiro, 5 fev. 1838 , n. 139 , p. $1-3$.

6 Fundado em 1836, O Cronista foi um periódico que, de saída e ancorado no lema - "Há no mundo quem tenha mais juízo que Voltaire, mais força que Napoleão - é o povo" -, não se aliou a nenhuma corrente partidária, tentando manter alguma independência em relação às rusgas que animavam o debate público entre o Governo e o Parlamento. No entanto, sobretudo ao adotar uma nova postura de oposição sistemática ao então regente o padre Diogo Antônio Feijó, o jornal foi se encaminhando para o lado, ou melhor, para os braços do núcleo político que, pouco depois, formaria o Partido Conservador.

7 Fundado em 1837, o Gabinete de Leitura era periódico semanal, voltado tanto para a disseminação da literatura no país quanto para a difusão do hábito de leitura entre os brasileiros, e mais notadamente da prosa
} 
A chamada obra literária de Firmino Rodrigues da Silva é muito escassa, tanto que a ele, do que até hoje se conhece, é atribuído, além dos três contos, a autoria de pouco mais de dez poemas. Se, por um lado, e antes de mais nada, o autor ficou conhecido na tradição literária sobretudo pela grande repercussão da famosa nênia, por outro, e a despeito da irregular qualidade estética, os três contos também contribuíram para a disseminação do gênero no Brasil. Aliás, não custa lembrar que a literatura nacional de qualquer país não é formada apenas e tão somente por obras de alta qualidade estética, a obra de menor qualidade - como já observou Antonio Candido (2004) - também atua na consolidação de um movimento literário.

Numa obra pioneira sobre o desenvolvimento do conto no Brasil, Barbosa Lima Sobrinho, fixando-se em parâmetros histórico-cronológicos, elencou uma série de autores que publicaram seus textos no período de 1830 a 1840. Entre tais autores, chamados de precursores, Lima Sobrinho incluiu dois contos de Firmino: "Um sonho" e "Três desejos" (1960, p. 135). No entanto, é importante ressaltar que o terceiro conto, "Mariana Pinta", citado tanto na introdução do livro de Lima Sobrinho inicialmente como "Mariano Pinto" - "Firmino Rodrigues da Silva, autor de Os Três Desejos e de Mariano Pinto" (idem, p.17-18) - quanto no pequeno texto de apresentação de autor apenas como "Mariana" - "Publicou em O Cronista os escritor Os três desejos e Mariana, com as iniciais F. R. da S."(idem, p. 135) -, nunca foi, ao que tudo indica, reproduzido uma segunda vez desde a primeira publicação no jornal $O$ Cronista, em 13 de fevereiro de 1838. Obviamente, tal fato confere ao terceiro e esquecido conto de Firmino algum ineditismo literário.

Se hoje a distância temporal dificulta, e muito, o encontro da possível explicação que norteou a exclusão de "Mariana Pinta" da antologia organizada por Lima Sobrinho, a sua preocupação temática, centrada na sobrevalorização histórica do Padre António Vieira como ardoroso defensor dos indígenas brasileiros, justifica por si a necessidade de trazer novamente à luz este pequeno texto de Firmino Rodrigues da Silva. Sobretudo quando se leva em conta que a temática indianista do conto, no contexto histórico de seu aparecimento em 1838, relaciona-se com os primeiros passos do próprio movimento romântico brasileiro e, por tabela, com o início do processo

\footnotetext{
ficcional. Segundo Marlyse Meyer, o Gabinete de Leitura "é certamente a mais importante publicação para o estudo dos primórdios do romance brasileiro; publicou uma série de novelas de Pereira e Silva com nítida influência de Luiza, de Mme. Helme, muitas crônicas, primeiro em tradução, depois originais, visivelmente imitadas de Paul de Kock” (Cf. MEYER, 1996, p. 430).
}

de afirmação estética, em termos nacionalistas, do indianismo literário ${ }^{8}$.

\section{O padre e a índia}

De saída, no entanto, é importante observar que existem dois problemas pontuais que permeiam a história de "Mariana Pinta". O primeiro se refere às especificidades teóricas que caracterizam o conto como gênero literário. Em outras palavras, a despeito da própria elasticidade do conceito do conto, o texto de Firmino apresenta, por assim dizer, um caráter estrutural algo hibrido. A rigor, o texto é alguma coisa indefinida entre crônica histórica e conto, misturando informações históricas com a ficcionalização de um fato particular da vida do Padre António Vieira, quando de sua estada no Brasil, entre 1653 e 1661 . Ou, de modo mais preciso, o momento da prisão e, consequentemente, de sua expulsão do Brasil.

Por outro lado, o segundo problema está centrado na evidente divergência em torno do próprio título, explicitada pelas passagens citadas da antologia de Lima Sobrinho. Como se mostrou, no livro do crítico, o conto é intitulado ora como "Mariano Pinto", ora como apenas "Mariana". No entanto, defende-se aqui que, na verdade, o conto se chama "Mariana Pinta". Para elucidar o problema, é importante de início recorrer à edição do jornal $O$ Cronista em que o conto foi publicado, o título que aparece é "Mariana Pinto". Entretanto, o verdadeiro título se esclarece quando, por sua vez, recorre-se à obra que foi usada por Firmino Rodrigues como fonte histórica, ou seja, a primeira e encomiástica biografia do jesuíta português, $A$ vida do apostólico Padre António Vieira (1746), do também jesuíta André de Barros. Na parte III do referido livro, em que é narrada a prisão de Vieira, quando Barros se refere ao primeiro aparecimento da indígena, é possível ler o seguinte: "Uma Índia, chamada Mariana Pinta, tinha valor para quebrar este encanto, e caridade para desprezar temores" (BARROS, 1746, p. 327). Portanto, é plausível afirmar que, na realidade, o título do conto de Firmino seria, de fato, "Mariana Pinta", o que, inclusive, pode sugerir que a incorreção que saiu em o Cronista - "Mariana Pinto" - tenha sido provavelmente causada por um erro de natureza tipográfica.

Esclarecidos os problemas de gênero e do título, pode-se dizer que, em linhas gerais, o enredo do conto é focado na chegada do Padre António Viera ao Maranhão, destacando, ao lado da prodigiosa natureza brasileira,

\footnotetext{
Como se sabe, a historiografia literária considera que o romantismo brasileiro foi iniciado no ano de 1836 com a publicação do livro Suspiros poéticos e saudades, de Gonçalves de Magalhães, e da Revista Niterói. Com influência direta do romantismo francês, tanto o livro quanto a revista foram publicados em Paris.
} 
a sua então permanente luta contra a escravização dos indígenas. Já na parte final, e por descontentar os interesses dos colonos locais, o Padre Viera acabou sendo preso e, por fim, deportado para Lisboa. No entanto, ainda isolado na prisão, o jesuíta recebeu a inusitada ajuda da indígena, Mariana Pinta, que, por sua vez, e durante todo o período de cárcere, providenciou-lhe comida. Por causa de tal gesto, Mariana teve a casa queimada pelos colonos, mas, em reconhecimento à sua coragem e, sobretudo, ao seu sentimento de caridade, os próprios jesuítas se responsabilizariam, mais tarde, pela educação de um de seus filhos, que viria a se tornar sacerdote.

Personagem emblemático das histórias de Portugal e do Brasil, o Padre António Vieira, cuja infância fora aquecida "pelo sol brilhante dos trópicos", é representado no conto de maneira hiperbólica, sobretudo no que se refere à sua reiterada defesa dos indígenas brasileiros, sendo, inclusive, ao longo do texto, comparado ao frei espanhol Bartolomeu de Las Casas que "troou contra os assassinos dos descendentes dos Incas, e Vieira ergueu-se no Brasil o defensor dos filhos de Tupá".

Em suma, ao insistir que "o célebre orador" Padre Vieira "quer defender os infelizes", Firmino Rodrigues, ao também ressaltar no seu texto o sentimento de caridade de Mariana, contribui, mesmo que de maneira tímida e à sombra do jesuíta, para a introdução da personagem indígena na cena literária local. Além do mais, a sobrevalorização do gesto de Mariana se adequava perfeitamente ao ansiado espirito romântico que, por assim dizer, também começava a dar seus primeiros passos na literatura brasileira, o que, mais uma vez, justifica a óbvia necessidade de trazer à luz este esquecido conto de Firmino Rodrigues da Silva.

\section{APÊNDICE9 \\ Crônicas Brasileiras \\ Mariana Pinta}

Não foram insignificantes motivos que conduziram o Padre António Vieira as margens do Amazonas, desse formidável rei dos rios que luta peito a peito com o oceano, reúne-o e lhe invade o domínio. A uns coube a sorte de varar florestas ainda não calcadas pelo pé do homem civilizado, de afrontar perigos imensos, extraordinários para descobrirem os veios das suspiradas minas; enquanto que outros embevecidos na contemplação de tão estupendas maravilhas, devorados pelo amor da ciência iam indagar do gênio do rio a revelação de seus mistérios, o número de seus feudos, quais as nações que lhe bordavam as margens.

Assuntos de maior transcendência guiaram o celebre orador de Portugal às majestosas florestas do Grão-Pará. Era o amor da religião e da humanidade quem o arrancava do meio de seus triunfos, da admiração dos reis, e do respeito e veneração dos povos. Educado na América desde a mais tenra infância, aquecido pelo sol brilhante dos trópicos, ele preferia as florestas virgens do mundo da natureza aos decantados monumentos que adornam o mundo da civilização - a Europa.

Era então o tempo em que a cobiça e a avidez do ganho mais destruidoras que a peste, mais insaciáveis

SILVA, Firmino Rodrigues. Mariana Pinta. O Cronista, Rio de Janeiro, 5 fev. 1838, n. 139, p. $1-3$. que a sede, tornavam ignóbeis e infames os dois benefícios da civilização. As cordilheiras gemiam com o despedaçamento de suas entranhas, e as florestas se horrorizavam com os últimos arrancos desses valentes filhos do deserto, que preferiam a morte dos combates ao lento suplicio da escavação das minas.

Contra tamanhos atentados ergueram-se, poucos sim, mas generosos brados. $\mathrm{O}$ mundo já não era governado pelo egoísmo, nem povos e nações inteiras atadas ao carro vencedor iam aviltar-se no pó do capitólio. Uma religião radiante havia dissipado as trevas do paganismo, o Filho do Eterno encarnara no seio de uma Virgem imaculada, e seus ditames e sua moral tinham regenerado o mundo. - Las Casas troou contra os assassinos dos descendentes do Incas, e Vieira ergue-se no Brasil o defensor dos filhos de Tupá.

Embalde instam o rei e a corte porque não parta o missionário: - não, ele quer defender infelizes, propagar na América a vinha do Senhor. Embalde a corte lhe acena com as palmas e as vitorias do gênio; que importam elas? - Sua missão é mais augusta, um anjo revelhou-lha, - é o céu quem o envia. Quem sabe se uma coroa do martírio... Oh! E o que mais anseia um missionário!

Já o galeão, que devia em troco de ninharias voltar pejado de ouro para enriquecer a metrópole, aprestava-se para a viagem: a âncora a pouco e pouco se ia 
suspendendo, já o Tejo como que o empurrava para longe de si, e os marinheiros saudosos entoavam a canção da despedida.... quando a um sinal de bordo estremece o navio com o baque da âncora que de novo encrava-se no leito do rio. Que será? Um enviado da parte de El-Rei que terminantemente se opõem a partida. Inúteis esforços, em vão os teólogos se reúnem para decidirem se é mais vantajosa à Religião a ficada ou a ida do missionário; pode mais o céu que as ordens do soberano; na primeira ocasião partiu...

\section{Tão brandamente os ventos o levavam \\ Como quem o céu tinha por amigo.}

Chegado ao Maranhão passou-se depois ao Pará onde a fama de seu nome já tinha ecoado, e foi recebido em triunfo. Sem contemplações a interesses humanos, como superior que era a todos eles, o missionário por toda parte expande enérgico os sentimentos de seu coração: ora convoca os principais do país para advogar a causa dos indígenas, ora embrenha-se pelas florestas a dentro, regenerando as almas na água misteriosa do batismo, anunciando aos gentios uma religião pura, cheia de bondade e de esperança.

Quão belo não seria vê-lo com essa figura majestosa e respeitável, essas vestes talares do sacerdócio, esses olhos vivos e preto cintilando engenho, essa palavra que aterrorizara os ímpios da Batavia, unir sua voz aos sibilos dos ventos, ao ruído das cataratas, aos uivos do tigre, às ruidosas exclamações dos filhos das florestas! Os arcos prestes a desprender a seta que não erra caiam a seus pés, e os braços, acostumados a lutar com a natureza em forças, erguiam no meio do deserto o sinal da redenção. Não eram templos elevados pelo orgulho dos homens a topetar com as nuvens que abrigavam os fiéis, uma simples capela de palma simbolizava a inocência de seus corações sinceros; - dir-se-ia que a singeleza rústica dos tempos primitivos da Igreja havia reaparecido na América.

Tanto entusiasmo, tão fervorosa devoção pela causa dos Índios não podia deixar de acusar-lhe inumerosos inimigos no meio de uma sociedade gangrenada pela corrupção e avidez de ganho. - Seus compatriotas opuseram-se com toda a energia a causa dos desvalidos. Vieira, conhecendo os tramas de seus inimigos, escreve a El-Rei dando parte de tudo que havia acontecido, pedindo proteção aos Índios; as cartas foram interceptadas e voltaram as mãos daqueles que mais encarniçados se haviam mostrado para com eles; tudo foi patente, o raio já lampeja sobre a cabeça do missionário, é mais uma prova - que a eternidade é a recompensa do sacrifício.

Era um belo dia de festa no colégio dos Jesuítas; os sinos tocavam santos, o símbolo da inocência e da pureza, a hóstia imaculada em sacrifício à Divindade aos céus subia, enquanto que os fiéis ajoelhados batiam nos peitos pedindo misericórdia ao cordeiro de Deus; as nuvens de incenso e mirra despendidas dos turíbulos compassados, e os sons melancólicos do órgão pareciam envolver todos os fiéis em uma atmosfera de harmonia e perfumes... Eis que vozes confusas vem interromper a meditação dos fiéis, um grupo de colonos entra armado e arranca do Altar os ministros do Crucificado. Como aquele que mais venerado era entre os seus, foi Vieira o primeiro que buscavam, sem o maior sobressalto este se apresenta às turbas destemido.

Que é da tua sabedoria e artes? Porque te não livras deste conflito? dizia-lhe um: Se és santo porque não fazes com que sucumbamos? repetia-lhe outro. Todas estas blasfêmias ouvia o missionário, mas sua boca não dava uma palavra. Embalde a tempestade embravecida arroja suas fúrias contra o Chimborazo, a bonança vem e acha-o no mesmo lugar - imóvel.

Depois de atravessar as ruas públicas, foi o Padre Vieira conduzido à prisão, à ermida de São João Batista. - Notável coincidência! O pregador do deserto, aquele que havia anunciado ao mundo a vinda do Redentor hospedou em seu templo um pregador do deserto, que também viera anunciar a religião do Crucificado às nações desconhecidas do novo mundo.

Sentinelas estavam postadas para que ninguém ousasse falar ao missionário. A Providência porém não desampara os seus escolhidos, no meio do deserto faz chover maná e brotar arroios de água cristalina do âmago das rochas.

Havia por aí perto uma Índia, evocada as trevas da idolatria pelo zelo de Vieira. Foi Mariana Pinta, informada de quanto acontecera ao pai dos Índios, e bárbara, ainda há pouco retraída a fereza do deserto, compadece-se de seus infortúnios, enquanto os próprios concidadãos iníquos negavam-lhe até o pão da indigeneia.

Preciso foi iludir a vigilância dos guardas, entranhar-se entre as sombras da noite, para sem ser vista lançar aos pés do missionário uma oferenda, a única de que podia dispor - uma parte de seu alimento.

Entregue a mais profunda meditação sobre a perversidade dos homens, e o desamparo em que ficavam os Índios, ajoelhado ante o altar, cujos círios iluminavam-lhe a face, alheio a todas as considerações mundanas, roga o missionário ao Deus de piedade, que faça chover torrentes de bênçãos sobre os mesmos que o perseguem. Mariana entra e pasma.... como a pobre neófita podia compreender esses êxtases de devoção, essa absorção de todas as faculdades humanas em um só ponto - na contemplação do Criador? Não se atrevendo a despertá-lo, ela vai depor o pequeno cabaz em que trazia a refeição, mas ele viu-a: - Mariana, que temeridade! Nunca, nunca mais, teme a malvadeza de meus inimigos. 
Mariana não respondeu, mas seus olhos ergueram-se para o céu!

Ao sair as sentinelas a viram e a maltrataram, não obstante, no dia seguinte, às mesmas horas, a neófita desempenhou sua tarefa.

Era alta noite, quando o reflexo de um incêndio enrubescia todo o interior da capela, o missionário ergue-se da oração, pensando que seus inimigos tivessem lançado fogo ao templo de João; debruça-se em uma janela e vê ao longe a choupana da pobre neófita, que se desfazia em chamas, depois conheceu-lhe a voz e ouviu que ela dizia: - Queimaram minha casa! Está bom, cozinharei no meio do campo.

Até que Vieira fosse mandado para o Maranhão, Mariana não descontinuou suas visitas. Daí a mais de 28 anos, no dia 3 de junho de 1867 a capital do Pará estava risonha e alegre como em dia de festa que era; notável concurso de gente que empeçavam umas nas outras dirigia-se a igreja, em cujas torres

Tine festivo o repetido bronze.
De todas as aldeias vizinhas tinham concorrido quase todos os habitantes para tão assinalado dia com suas vestes domingueiras; o templo estava ricamente adornado, era um dia de missa nova. Depois de os padrinhos terem dado água às mãos ao celebrante, colocou-se este no meio do altar; todos os olhos se fitaram em seu rosto, todas as mães invejavam a sorte de uma Índia que ali estava, quebrada pelos anos: foi ela segundo as cerimônias da nossa Igreja quem primeiro beijou as mãos do sacerdote... Oh! Que alegria, que contentamento não sentiu esse coração, vendo seu filho ministro do Deus vivo! Os Jesuítas, em reconhecimento ao que Mariana havia praticado para com o Padre Vieira, educaram-no e o filho da indígena foi colocado na Tribo dos Levitas.

Mariana sempre que se recordava desse tão ditoso momento, dizia as suas amigas; - Nunca tive maior prazer em minha visa; já posso morrer contente, e enxugava uma lágrima que se demorava sobre as rugas de seu alquebrado semblante.

F. R. da S.

\section{Referências}

BARROS, André de. A vida do apostólico Padre António Vieira. Lisboa: Nova Oficina Silviana, 1746.

CANDIDO, Antonio. O direito à literatura. Vários escritos. 4. ed. São Paulo: Duas cidades; Rio de Janeiro: Ouro sobre Azul, 2004. p. 162-191.

GALVÅO, Walnice Nogueira. Indianismo revisitado. In: LAFER, Celso (Org.). Esboço de figura: homenagem a Antonio Candido. São Paulo: Duas Cidades, 1979. p. 379-391.
LIMA SOBRINHO, Barbosa. Os precursores do conto no Brasil (Introdução, pesquisa e seleção). Rio de Janeiro: Civilização Brasileira, 1960. (Panorama do conto brasileiro, 1).

MARQUES, Wilton. O poeta sem livro e a pietá indígena. Campinas: Editora da UNICAMP, 2015.

MEYER, Marlyse. Folhetim: uma história. São Paulo: Companhia das Letras, 1996.

Recebido, p. 27 de janeiro de 2017 Aprovado, p. 28 de janeiro de 2017 Contato:willjmufscar@gmail.com 